\title{
Cadeia de valor de megaeventos: um estudo de caso de uma feira de negócios agropecuários
}

\section{Value chain of mega events: a case study of an agricultural trade fair}

\author{
Fabrício Silva Barbosa ${ }^{1}$ \\ Annibal José Scavarda ${ }^{2}$
}

GESTÃO

PRODUCÃ̃O

ISSN 0104-530X (Print) ISSN 1806-9649 (Online)

\begin{abstract}
Resumo: O turismo de eventos definitivamente consolidou-se como uma das ramificações do turismo que mais favorecem o desenvolvimento econômico das localidades onde se realizam. No Brasil, a prática de megaeventos impulsiona o segmento e alavanca o setor de serviços que atua na localidade. Contudo, para que atendam às expectativas de seus organizadores, alguns processos necessitam ser introduzidos de forma adequada. A cadeia de valor aparece como uma ferramenta indispensável nas suas realizações. Este artigo teve como objetivo analisar a Feira de Negócios Agropecuários da Fronteira Oeste - Fenaoeste, realizada em São Borja/RS - Brasil, tomando como base a cadeia de valor porteriana com uma adaptação das suas atividades primárias e secundárias com as lentes de serviços. De caráter qualitativo e exploratório, o trabalho teve como método um estudo de caso. Com base nas entrevistas com os especialistas e na literatura da área, apresentam-se pontos e questões estratégicos para a competitividade de megaeventos, em que os aspectos ligados à tecnologia de informações e ao envolvimento dos clientes internos e externos têm intensas influências. Para melhoria das atividades na busca de vantagens competitivas, sugere-se um uso mais intenso de tecnologia de informações principalmente no pós-evento, em que existe maior necessidade da interação humana com os clientes, que são coprodutores, para obtenção de conhecimento sobre estas partes interessadas. Para tanto, deve-se coordenar os aspectos de intangibilidade, perecibilidade e simultaneidade com atenção em pontos como treinamentos, divulgação do evento, riscos de contratação, sistemas de gestão e terceirização dos funcionários (com cuidado aos estratégicos) para promover produtos essenciais dos eventos: qualidade de serviços, experiência do cliente e show. A universidade pode ajudar neste desenvolvimento. Ainda que esta pesquisa não seja de caráter conclusivo, são apresentadas algumas reflexões relevantes sobre a cadeia de valor de megaeventos juntamente com propostas de pesquisas futuras.
\end{abstract}

Palavras-chave: Turismo; Serviços; Atividade primária; Atividade de apoio.

\begin{abstract}
Event tourism is definitely consolidated as one of the ramifications of tourism that most contributes to the economic development of the localities where it is held. In Brazil, the practice of mega events boosts the segment and leverages the local services sector. However, to meet the expectations of its organizers, some processes need to be introduced properly. The value chain appears as an indispensable tool in their achievement. This paper aims to analyze the Business, Agriculture and Livestock Fair of the Western Border - Fenaoeste, held in the municipality of São Borja, Rio Grande do Sul state, Brazil, taking as a basis the Porterian value chain with an adaptation of its primary and support activities with the services lenses. This case study uses a qualitative and exploratory methodology. Based on interviews with experts and on the specific literature, it presents strategic points and issues for the competiveness of mega events, where the aspects related to the information technology used and the involvement of internal and external customers have intense influence. For the improvement of activities in the search for competitive advantage, it suggests a more intensive use of information technology, especially in the post-event phase, where there is a greater need for human interaction with customers, who are co-producers to obtain knowledge about these stakeholders. To this end, it is necessary to coordinate the aspects of intangibility, perishability, and simultaneity with attention to issues such as training, disclosure of the event, recruitment risks, management systems, and outsourcing of employees (with caution in relation to the strategic ones) to promote key products of the events: service quality, customer experience, and show. The university can assist in this development. Although this research is not of conclusive nature, some relevant reflections on the value chain of mega events are presented along with proposals for future research.
\end{abstract}

Keywords: Tourism; Services; Primary activity; Support activity.

${ }^{1}$ Eixo Tecnológico Turismo, Hospitalidade e Lazer, Instituto Federal Farroupilha, Campus São Borja, São Borja, RS, Brasil, e-mail: fabricio.barbosa@iffarroupilha.edu.br

${ }^{2}$ Pós-graduação em Engenharia de Produção, Escola de Engenharia de Produção, Universidade Federal do Estado do Rio de Janeiro - UNIRIO, Rio de Janeiro, RJ, Brasil, e-mail: annibal.scavarda@unirio.br

Recebido em Jan. 31, 2014 - Aceito em Jun. 24, 2015

Suporte financeiro: Nenhum. 


\section{Introdução}

É cada vez mais perceptível que o turismo assumiu um papel de grande relevância no cenário econômico de muitos países. Ele tem despertado o fascínio da comunidade acadêmica para o desenvolvimento de novos projetos e pesquisas, assim como o de empresários pertencentes ao trade, interessados em fazer novos investimentos nesta atividade, que já é apontada como umas das mais importantes em relação à economia mundial, encontrando-se atrás apenas de economias como minério de ferro, soja em grãos, indústria automobilística e petróleo bruto (Barbosa, 2010; Banco Central do Brasil, 2013; Brasil, 2013).

Ele é considerado uma atividade plurissetorial, uma vez que engloba a utilização de diferentes profissionais e mistura uma grande quantidade de serviços necessários para que seja implementado e desenvolvido de forma satisfatória. Os resultados da junção de todos estes serviços estão atrelados a diversos setores culturais, ambientais e sociais, que fazem com que o turismo impulsione a economia pelo reflexo do efeito multiplicador.

A prestação de serviços por meio da realização de megaeventos promoveu o surgimento de uma nova tipologia de turismo, que deu origem ao turismo de eventos, que se destaca assumindo o papel de impulsionar a economia de diferentes destinações e localidades turísticas. Watt (2004, p. 15) explica que os

[...] eventos de comunidades locais podem ser definidos como atividades estabelecidas para envolver a população local em uma experiência compartilhada, visando seu benefício mútuo.

Allen et al. (2010, p. 128) utilizam o recorte "evento especial" e definem evento como sendo um

[...] ritual, apresentação ou celebração específica, que tenha sido planejado com o intuito de marcar datas especiais ou atingir objetivos e metas de cunho social, cultural ou corporativo.

Inseridos nas atividades atreladas à prestação de serviços, os eventos alavancam a economia local e promovem a destinação em que se desenvolvem. Nesta perspectiva, Getz (1993) salienta a importância da comunidade no processo de execução de eventos, que se torna responsável por grande parte do sucesso deles.

Segundo Telles \& Previatti (2012), o turismo de eventos é um potencial multiplicador que gera diferentes atrativos, inclusive o próprio turismo, ou seja: esta atividade possibilita aos que participam do processo, como prestadores de serviços, retornarem e participarem da atividade como turistas. Este pensamento é complementado por Silva (2008, p. 2) quando afirma que os eventos
[...] tornaram-se elementos de transformação social de aculturação de massas, além de serem os maiores e melhores geradores de conteúdo para a mídia.

Estudos divulgados pelo World Travel \& Tourism Council (2013) apontaram o Brasil como o líder da América Latina na realização de eventos internacionais. A pesquisa mostrou que este segmento movimentou aproximadamente $\mathrm{R} \$ 131$ bilhões e impactou diretamente o Produto Interno Bruto brasileiro (PIB) no ano de 2011, o que representa uma estimativa de crescimento de 7,8\% para o ano de 2012 (Associação Brasileira de Empresas de Eventos, 2012). O WTTC classificou o Brasil em sexto lugar no ranking mundial dos impactos causados pelo turismo por ocasião da realização de eventos, gerando empregos diretos e indiretos, políticas públicas específicas e impactos diretos e indiretos no PIB nacional (Associação Brasileira de Empresas de Eventos, 2012; World Travel \& Tourism Council, 2013). O Ministério do Turismo tem introduzido atividades por meio do Plano Nacional de Turismo com recursos oriundos do Governo Federal, que previu ações para acelerar o projeto de melhorias nas cidades-sede da Copa do Mundo de 2014 e no Rio de Janeiro, cidade-sede dos Jogos Olímpicos de 2016 (Mercado\&Eventos, 2012).

A cidade de São Borja está localizada na região da fronteira oeste do Rio Grande do Sul, onde faz fronteira com a cidade argentina de Santo Tomé, e possui população total de 61.662 habitantes (IBGE, 2012). Destacam-se os atrativos culturais, turísticos do agronegócio e, mais recentemente, a transformação da cidade em um grande polo educacional.

Este trabalho teve como objetivo analisar a cadeia de valor de um megaevento por meio do estudo da Fenaoeste, Feira de Negócios Agropecuários da Fronteira Oeste de São Borja/RS, tomando como base a cadeia de valor proposta por Porter (1999) com uma adaptação das suas atividades primárias e secundárias com as perspectivas de serviços. Procurou-se realizar a investigação por meio das opiniões dos especialistas e literatura da área evocando questões gerenciais envolvidas de acordo com o ponto de vista dos especialistas e, então, fazer reflexões sobre as peculiaridades desta cadeia de valor para auxiliar sua melhoria.

Realizada pelo Sindicato Rural da Cidade de São Borja, a Fenaoeste é tida como o maior evento do gênero realizado na região. De caráter qualitativo e exploratório, a investigação teve como método a estruturação de um estudo de caso, para que então fosse realizada uma análise da cadeia de valor de eventos. A coleta de dados foi realizada por meio de uma entrevista ao Secretário geral da presidência do Sindicato Rural de São Borja e oito empresários que atuam como expositores no Parque de Exposições durante o evento. Um questionário semiestruturado subsidiou esta etapa da pesquisa. O modelo aplicado 
nesta investigação foi o modelo da cadeia de valor proposto por Porter (1999).

A seção seguinte trata da revisão da literatura, iniciando com os aspectos de logística e cadeia de suprimentos para depois esclarecer a distinção delas com cadeia de valor e, então, focar cadeia de valor. A seção apresenta como a cadeia de valor será abordada nesta pesquisa por meio de algumas modificações no modelo de Porter (1999) para adequá-la a eventos e depois os aborda. Depois se tem as seções de metodologia, análise da cadeia de valor da Fenaoeste e questões estratégicas. A seguir a conclusão, limitações e pesquisas futuras são tratadas.

\section{Revisão da literatura}

\subsection{Considerações acerca do conceito de logística e cadeia de suprimentos (SC)}

$\mathrm{Na}$ Antiguidade, os produtos desejados eram produzidos onde as pessoas gostariam de consumi-los. Todos os produtos, incluindo alimentos, estavam amplamente dispersos e disponíveis em abundância apenas em certos períodos do ano. Sendo assim, eles deveriam ser consumidos de imediato e nos locais onde se encontravam, ou então deveriam ser armazenados para uso posterior. Todo este processo fazia-se necessário por não haver sistemas de transporte e distribuição organizados, bem como sistemas de armazenagem bem estruturados (Ballou, 2006). Conforme destaca Pires (2004), a logística como área de atuação e conhecimento humano já existe desde a Antiguidade e os livros tradicionais reforçam o caráter militar adquirido por esta disciplina.

Nas empresas, até as primeiras décadas do século passado, o departamento logístico desempenhava uma função secundária. Atualmente, porém, observa-se o surgimento de novas formas de trabalhar-se com a logística, que foram impulsionadas por uma série de acontecimentos ocorridos nas últimas décadas, notadamente após a Segunda Guerra Mundial. A partir deste período, esta disciplina tem crescido de forma contínua, não deixando de lado a sua ligação direta com a logística militar. Durante a referida guerra (1939-1945), a logística foi utilizada de forma global e estabeleceu-se uma ligação direta integrada a estratégias e táticas que serviam de apoio às atividades militares (Silva \& Musetti, 2003). O conceito de logística também acompanhou a sua evolução. Segundo Christopher (2011), foram necessários uns setenta anos para clarificar os princípios de gerenciamento logístico.

$\mathrm{Na}$ atualidade, a logística apresenta uma interface fundamental junto à produção e ao marketing, tornando-se instrumento de extrema e fundamental importância dentro dos processos. Na definição proposta pela Council of Logistics Management (CLM), a logística seria uma parte integrante daquilo que comumente se entende por cadeia de suprimento, demonstrando que é preciso a gestão eficiente de fluxos de bens, serviços e informações, desde a obtenção de insumos até sua distribuição.

Para Pires (2004, p. 47), uma cadeia de suprimentos (Supply Chain - SC) pode ser definida como "[...] os processos que envolvem fornecedores-clientes e ligam empresas desde a fonte inicial de matéria-prima até o ponto de consumo do produto acabado." Lee \& Billington (1993, p. 54) concebem que

[...] uma SC representa uma rede de trabalho (network) para as funções de busca de material, sua transformação em produtos intermediários e acabados e a distribuição desses produtos acabados aos clientes finais.

No entendimento de Simchi-Levi et al. (2006, p. 27), a gestão da cadeia de suprimentos é:

Um conjunto de abordagens utilizadas para integrar eficientemente fornecedores, fabricantes, depósitos e armazéns, de forma que a mercadoria seja produzida e distribuída na quantidade certa, para a localização certa e no tempo certo, de forma a minimizar os custos globais do sistema ao mesmo tempo em que atinge o nível de serviço desejado.

No entendimento de Bowersox et al. (2014), a cadeia de suprimentos oferece uma estrutura para negócios e seus fornecedores, que trabalham em conjunto para que mercadorias, serviços e informações cheguem até os consumidores da forma mais rápida e eficiente, ocasionando a satisfação destes. De acordo com os autores citados, a logística torna-se uma ferramenta de extrema importância para a criação de vantagens competitivas no mercado turístico, no qual está inserido o segmento de turismo de eventos. Segundo Rusko et al. (2009), os estudos que envolvem a gestão da cadeia de suprimentos tornaram-se comuns em pesquisas que envolvem a gestão de negócios. Apesar da popularidade desta temática e das discussões que envolvem a utilização da SC como ferramenta, esta tem sido esquecida no turismo, fazendo com que pesquisadores de diferentes instituições de vários lugares do mundo demandem esforços para introduzir novos estudos atrelados à atividade turística.

Como afirmam Bowersox et al. (2014), a gestão da cadeia de suprimentos compreende empresas que colaboram na busca por um posicionamento estratégico que possa garantir a melhoria de seus serviços. Segundo os apontamentos de Sigala (2008), a intensa concorrência dos mercados tem obrigado as empresas a repensarem o formato das cadeias de suprimentos, em especial as empresas prestadoras de serviços. A autora aponta a existência de um novo formato de cadeia de suprimentos, cujo formato de aglomeração propicia maior agilidade e flexibilidade em seu funcionamento. Operações da cadeia de suprimentos exigem processos gerenciais que passam 
em áreas funcionais dentro de empresas individuais e conectam parceiros e clientes fortalecendo as relações comerciais. Para Wood (2004, p. 220), "[...] a cadeia de suprimentos opera em looping materiais e produtos acabados, todas as informações e transações."

De acordo com Stock (2009), entre o período de 1993 e 2005 foram realizados alguns estudos que tinham como objetivo demonstrar a aplicabilidade da logística empresarial como ferramenta dentro das organizações. Por ocasião desta pesquisa, foram encontrados dois artigos que mostravam que o modelo mais viável para aplicação nas empresas de serviços seria o da aplicação da cadeia de Porter (1999), que será visto mais detalhadamente na seção 2.2: "entendimento da cadeia de valor". Ballou (2006) corrobora esta teoria ao afirmar que a logística pode apresentar uma característica mais operacional quando se consegue destacar a missão da logística como fornecedora de mercadorias e serviços, a qual tem por objetivo satisfazer as necessidades e exigências do cliente da forma mais eficiente possível.

Stock (2009) também salienta que o primeiro estudo encontrado, realizado por Armistead \& Clarck (1993), propunha apenas uma reestruturação das estratégias aplicadas ao setor de serviços; para isso haveria a necessidade de uma nova interpretação da cadeia de valor criada por Porter (1999). Para tanto, foi sugerida uma proposta de revisão de alguns modelos criados por autores como Albrecht \& Zemke (1985), responsáveis pela criação do modelo de customização de serviços. Para este modelo específico, foram indicadas três dimensões de contribuição: estratégia de serviço, sistemas e pessoas, que tornaram a prestação de serviços menos operacional. Stock (2009) afirma que o segundo estudo, realizado por Shostack (1984), Gummesson (1991) e Kingman-Brundage (1995) recebeu o nome de "mapeamento de serviços". Esse modelo deixava de fora algumas questões importantes, como a correlação entre estrutura e atividades operacionais e a relação entre os diferentes recursos utilizados no processo de prestação de serviços.

\subsection{Entendimento da cadeia de valor}

Existe muita confusão entre cadeia de valor e cadeia de suprimentos (Santos et al., 2010). Uma empresa é composta por uma cadeia de valor que é caracterizada por um conjunto de atividades integradas; o estudo destas atividades pode ajudar o entendimento desta empresa (Souza \& Mello, 2011). Ratificando este pensamento, Porter $(1985$, p. 89$)$ afirma que:

A vantagem competitiva não pode ser compreendida olhando-se para uma empresa como um todo. Ela deriva das muitas atividades discretas que desempenha, projetando, produzindo, entregando e apoiando o seu produto. Cada uma dessas atividades pode contribuir para a posição de custo relativo da empresa e criar a base para a diferenciação. A cadeia de valor desdobra a empresa em suas atividades estrategicamente relevantes, para compreender o comportamento dos custos e as fontes de diferenciação existentes ou potenciais. Uma empresa ganha vantagem competitiva executando estas atividades estrategicamente importantes de maneira mais barata, ou melhor, que seus concorrentes.

As lentes porterianas de cadeia de valor da empresa implicam que cada empresa avalie o procedimento de realização das suas atividades, a forma como estas atividades a influenciam e como elas impactam sua empresa, para poder potencializar as suas vantagens competitivas. As atividades da cadeia de valor geradas pela empresa respondem aos pedidos dos consumidores por meio dos produtos. $\mathrm{O}$ conjunto destas atividades estimula o valor rumo à obtenção de um maior desempenho (Koh \& Nam, 2005).

O modelo de Porter (1999) é bem conhecido e tem sido usado para explicitar os processos de criações de valores (Dehning et al., 2007). O modelo de Porter tem influenciado muito os estudos de estratégia nas últimas três décadas (Schneider et al., 2009), mas não existe um consenso em relação à cadeia de valor de Porter (Luchi \& Paladino, 2000; Rainbird, 2004; Koh \& Nam, 2005; Butler et al., 2007).

Nesta pesquisa, será adotado o conceito de que a cadeia de valor trata de um conjunto de atividades de valor de um produto restrito aos limites internos de uma empresa/instituição que criam as bases para o desenvolvimento de vantagens competitivas (Pires, 2004). Como se pode observar na Figura 1, as atividades podem ser primárias ("logística de entrada", "operações", "logística de saída", "marketing e vendas" e "serviços pós-vendas") ou de apoio ("infraestrutura", "administrativo-financeiro", "recursos humanos", "tecnologia da informação" e "suprimentos"); de acordo com o que estiver sendo estudado, a relevância de cada uma destas atividades poderá oscilar (Santos et al., 2010; Souza \& Mello, 2011).

O modelo da cadeia de valor de Porter (1999) continua sendo investigado em várias áreas e vem recebendo também algumas adaptações. Em um estudo de pequenas e médias empresas as atividades primárias foram categorizadas em atividades primárias essenciais e atividades primárias não essenciais (Bharati \& Chaudhury, 2012). Um estudo sobre o desenvolvimento de subsidiárias em empresas multinacionais, além de utilizar as atividades primárias e de apoio como blocos, explicitou a atividade de apoio de tecnologia da informação como um terceiro bloco: o bloco de desenvolvimento tecnológico que contém "pesquisa e desenvolvimento de longo prazo" e "pesquisa e desenvolvimento" (Edgington \& Hayter, 2013). Nas questões internacionais, por meio de uma análise de empresas estonianas (representando 


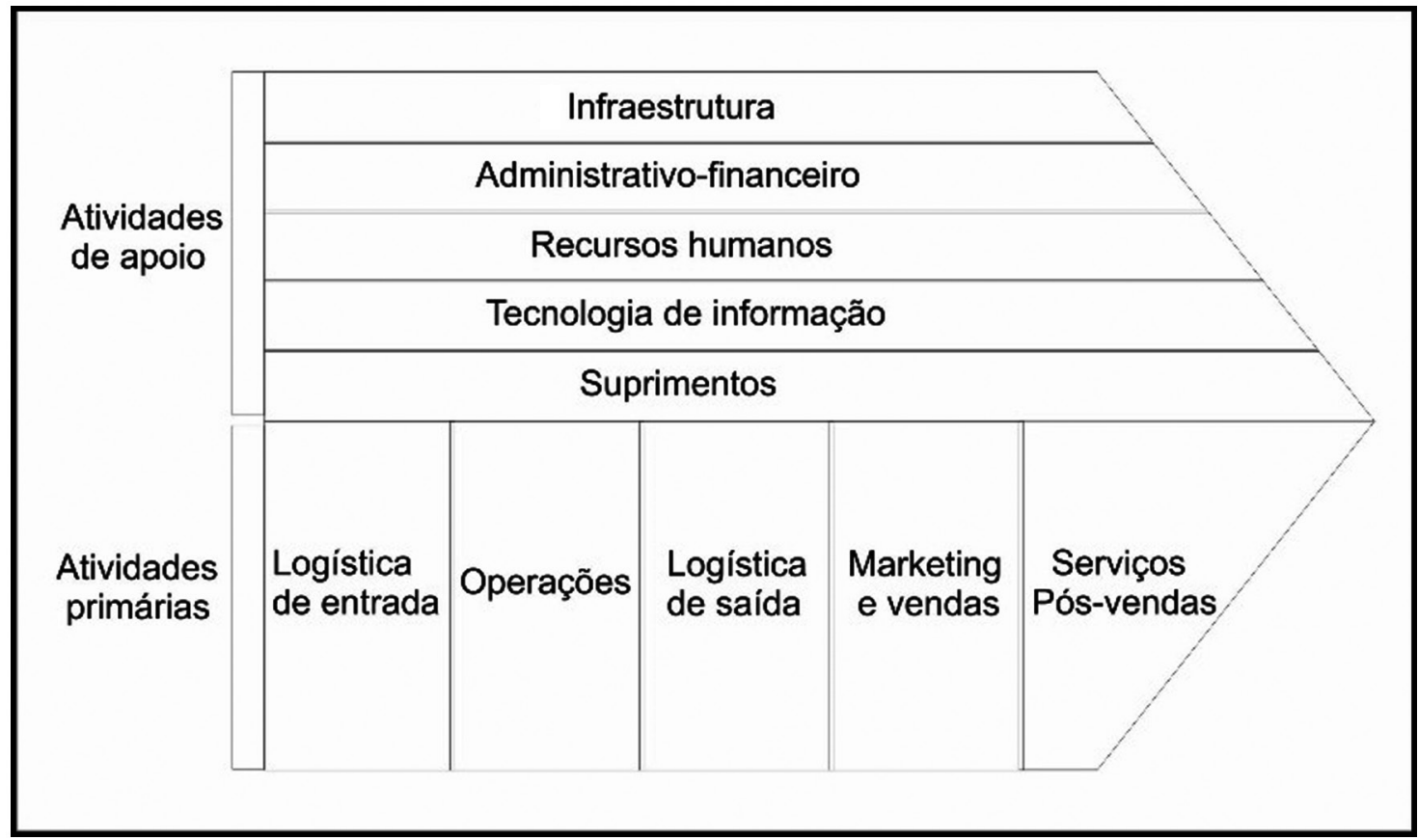

Figura 1. Cadeia de valores genérica criada por Porter. Fonte: Porter (1999, p. 35).

as empresas dos países do antigo bloco soviético), estudou-se como as empresas podem melhorar as suas posições na cadeia de valor e adaptar-se às modificações internacionais (Vadi \& Turk, 2009). Mesmo em pesquisas sobre questões dentro de um mesmo país, sugeriram-se alterações nas atividades; para a variação dos papéis de subsidiárias nacionais foram criados quatro grupos para as atividades de cadeia de valor: inovação, produção, vendas e administração (Rugman et al., 2011).

Até mesmo estudos específicos sobre questões universitárias propuseram modificações no modelo. O modelo foi adaptado para instituições universitárias em um estudo para reflexão sobre a oferta de ensino qualificado (De Conto et al., 2013) e em outro estudo para desenvolvimento de pesquisa (Karvonen et al., 2012), sendo que este segundo modificou a categorização das atividades de valor: atividades primárias ("geração e desenvolvimento de ideia", "pesquisa", "subcontratações em pesquisa e desenvolvimento empresarial", "desenvolvimento de rede", "disseminação de resultado" e "avaliação acadêmica") e atividades secundárias ("infraestrutura de pesquisa", "desenvolvimento de competência e gestão de recurso humano", "administração" e "arrecadação de verbas de projetos").

Observou-se até uma adaptação das atividades de valor para a cadeia verde de valor: atividades primárias - suprimento, reciclagem e pesquisa e desenvolvimento - e atividades secundárias manufatura e embalagem, marketing e promoção e educação (Kung et al., 2012). Outro estudo criticou as atividades de valor do Porter sublinhando que elas são limitadas em reconhecer que algumas funções (como gestão de instalações e as próprias atividades de apoio) permeiam as atividades primárias (Waheed \& Fernie, 2009). Fez-se a integração da cadeia de valor com a teoria da hierarquia de necessidades de Maslow para gerar um modelo de desenvolvimento sustentável baseado na cadeia de valor da sociedade, propondo a seguinte categorização das atividades: atividades primárias - necessidade psicológica, necessidade de segurança, necessidade de amor e pertencimento, autoestima - e atividades de apoio - infraestrutura da sociedade, governo, indústria e comércio (Walsh, 2011).

Estudos recentes apontam uma tendência de estudar a cadeia de valor ligada às questões tecnológicas e de sistemas de informações. A cadeia de valor vem sendo examinada como um dos métodos mais comuns de identificação de tecnologia (Arasti \& Moghaddam, 2010). Estudou-se como a tecnologia de informação impacta a cadeia de valor (Gorla et al., 2010). Uma pesquisa de terceirização da tecnologia de informação na manufatura e varejo simplificou as atividades primárias em logística interna, operações e logística externa (Gwebu et al., 2010). As compras via internet foram analisadas, resultando na adaptação do modelo. O funcionamento via click interferiu nas atividades de logísticas, logística interna e logística externa, que foram renomeadas para, respectivamente, logística interna do click e logística externa do click (Laffey, 2009). 
Outras propostas de aprofundamentos de pesquisas em cadeia de valor foram desenvolvidas como: nos recursos (Lin et al., 2012); na quantificação das atividades no biodiesel (Díaz-peña et al., 2013); na privacidade pelo Design (David \& Prosch, 2010); na competividade pela terceirização (Souza \& Rados, 2011); no meio do setor siderúrgico em inovação (Varandas et al., 2014); na hotelaria (Anjos et al., 2008); no relacionamento entre o tempo de vida dos ativos e as atividades (El-Akruti et al., 2013); nas estratégias de custos (Souza \& Mello, 2011); e nas alternativas estratégicas para a melhora na ovinocultura (Viana et al., 2013).

A partir do momento no qual as atividades de valor são desverticalizadas, elas passam a ser mais compartilhadas e gerenciadas além dos limites da empresa focal por diversas outras empresas, obtendo-se, assim, uma expansão geográfica dos sistemas produtivos. A cadeia de valor passa a ter uma forma diferente da sua forma convencional e a empresa focal passa a ter menos controle sobre todas as atividades de valor. Neste caso, cada uma destas empresas fora dos muros da empresa focal executa mais as atividades na cadeia de valor do produto, intensificando a sua participação do processo de criação de valor. Este valor se expande ao longo da cadeia de suprimentos definida pelo desenvolvimento das atividades nas próprias empresas participantes, visando o desenvolvimento do produto ao cliente final (David \& Prosch, 2010; Lollar et al.; 2010; Oliveira \& Leite, 2010; Santos et al., 2010; Christopher, 2011).

Com este sistema de valor, as cadeias de valor dos fornecedores fornecem inputs para as cadeias de valor da empresa focal e, consequentemente, os outputs da empresa focal tornam-se inputs para as cadeias de valor dos seus compradores (Walsh, 2011). Esta sequência de cadeias de valor forma a cadeia de suprimentos (Novaes, 2004). Mesmo com a ênfase de algumas pesquisas sobre a contribuição da cadeia de valor para a cadeia de suprimentos (Bovet \& Martha, 2000; Kirchmer, 2004; Taylor, 2005; Zokaei $\&$ Simons, 2006; Koh et al., 2007), ainda se explora pouco a análise da cadeia de valor como uma opção na gestão da cadeia de suprimentos para avaliar as competências centrais dos membros deste conjunto (Oliveira \& Leite, 2010).

As dificuldades enfrentadas na cadeia de suprimentos são vinculadas à caracterização da cadeia de valor da empresa focal. Por isto, para estudar a cadeia de suprimentos, torna-se oportuno estudar antes a cadeia de valor envolvida, principalmente da empresa focal. Desta forma, estudar a cadeia de valor pode ser um referencial para o estudo da cadeia de suprimentos, o que sublinha a ligação entre os dois estudos: cadeia de valor e cadeia de suprimentos (Santos et al., 2010). Neste artigo exploratório, será analisada a questão de cadeia de valor do megaevento de turismo da Fenaoeste de São Borja/RS por considerar que a Fenaoeste possui um amplo controle da gestão da sua cadeia de valor.

\subsection{A cadeia de valor de eventos}

Este artigo propõe para o estudo da Fenaoeste uma adaptação do modelo da cadeia de valor apresentado por Porter (1999). Como os conceitos das atividades de valor foram inicialmente influenciados nas suas formações pela gestão de bens de manufatura, neste estudo exploratório de gestão de serviços (eventos), as atividades primárias foram simplificadas para apenas duas atividades: "logística operacional" (para representar a atividade com mais característica de bens de manufatura) e "marketing e pós-venda" (para representar a atividade com mais característica de serviços). O intuito com isso foi de estruturar as atividades primárias na dicotomia serviços-manufatura para facilitar a compreensão das particularidades de serviços, conforme preconizado em Correa et al. (2007), Bitner \& Brown (2008) e Fitzsimmons \& Fitzsimmons (2014). Também como uma simplificação do modelo de Porter (1999) para serviços, nas atividades de apoio, não se incluiu a atividade de suprimentos por considerar que, na perspectiva de serviços, esta atividade de apoio pesa, em relevância, menos que as demais.

O turismo, por ser multidimensional e multifacetado, engloba várias atividades econômicas, de modo que estas atividades devem ser planejadas e estruturadas para que sejam introduzidas de forma que os objetivos sejam alcançados. Características referentes às atividades turísticas são encontradas dentro do segmento de eventos, que engloba um conjunto de serviços e leva à constituição de uma cadeia de valor. $\mathrm{O}$ grande desafio destas atividades é fazer com que estes serviços funcionem de forma sistemática, para que ocorra a perfeita integração dos processos de gestão (Goeldner et al., 2002; Cooper et al., 2007).

As atividades que estão diretamente relacionadas à cadeia de valor em serviços, especificamente no segmento turístico, contribuem diretamente na formação do custo final do produto turístico. Desta forma, a cadeia de valor pode ser compreendida como um dos componentes do produto turístico mais suscetível à percepção e avaliação do turista. $\mathrm{O}$ turismo mundial tem demonstrado um crescimento considerável se comparado com as últimas duas ou três décadas, o que beneficia diretamente todos que estão inseridos na cadeia de valor do turismo, tais como empresas prestadoras de serviços, poder público e os próprios consumidores de serviços turísticos (Song et al., 2013). O turismo envolve atividades de planejamento, implementação e gestão do fluxo de turistas, acomodação, lazer, recreação, 
entretenimento, mobilidade nos centros de interesse e suprimentos dos lugares de potencial atuação com bens de consumo com eficiência de desempenho nos quesitos de qualidade e custo (Karassawa, 2001; Stock, 2009).

Cada evento apresenta um conjunto de cadeias de valores diferenciadas, podendo ser definido como a junção de distintos segmentos que formam uma estrutura muito maior. Esta estrutura será representada pelos atacadistas, fornecedores de matérias-primas, insumos e fabricantes, alcançando seus objetivos no momento em que todos os seus integrantes conseguirem sistematizar as suas funções e justificarem a sua representatividade (Wood, 2004; Allen et al., 2010). Este pensamento é justificado por Britto \& Fontes (2004, p. 111) quando definem que:

Esta supervisão planeja, organiza, gerencia os recursos físicos, materiais, de apoio e manutenção, de segurança, e os recursos humanos necessários à realização do evento, dentro de cada etapa estabelecida.

O modelo proposto por Allen et al. (2010) pode auxiliar a interface entre o turismo e a cadeia de valor. Ele apresenta os componentes de eventos divididos em três fases distintas (Vide Figura 2). Evidencia a necessidade do planejamento adequado em todas as fases de um evento (Barbosa, 2013).

A primeira fase, definida como pré-evento, é o momento em que a ideia central está sendo concebida.
Ela geralmente é norteada pela elaboração de um briefing desenvolvido pela organização do evento. De acordo com o modelo proposto pelo autor, a segunda fase apresenta-se como a fase intermediária, chamada de transevento.

A segunda fase é o momento em que o projeto inicial pode ser alterado, assim como algumas correções podem ser realizadas, de acordo com os objetivos do organizador do evento. A separação das três fases dentro do planejamento torna o projeto flexível, permitindo que os organizadores decidam qual o melhor procedimento a ser adotado (Barbosa, 2013).

A terceira e última fase, chamada de pós-evento, é o momento em que toda a infraestrutura montada é retirada, bem como é realizada a desmontagem e devolução de equipamentos. Para o autor, o momento mais importante desta fase é a avaliação dos processos, na qual se torna possível analisar se as decisões tomadas durante o planejamento do evento foram adequadas, verificando se este alcançou seu objetivo. Nesta fase, também é possível fazer a verificação de prováveis problemas a serem corrigidos, objetivando o não comprometimento de eventos futuros.

\section{Procedimentos metodológicos}

Para analisar a cadeia de valor da Fenaoeste de São Borja/RS, optou-se pela realização da pesquisa de abordagem qualitativa, pois esta abordagem está focada em obter informações sob o ponto de vista

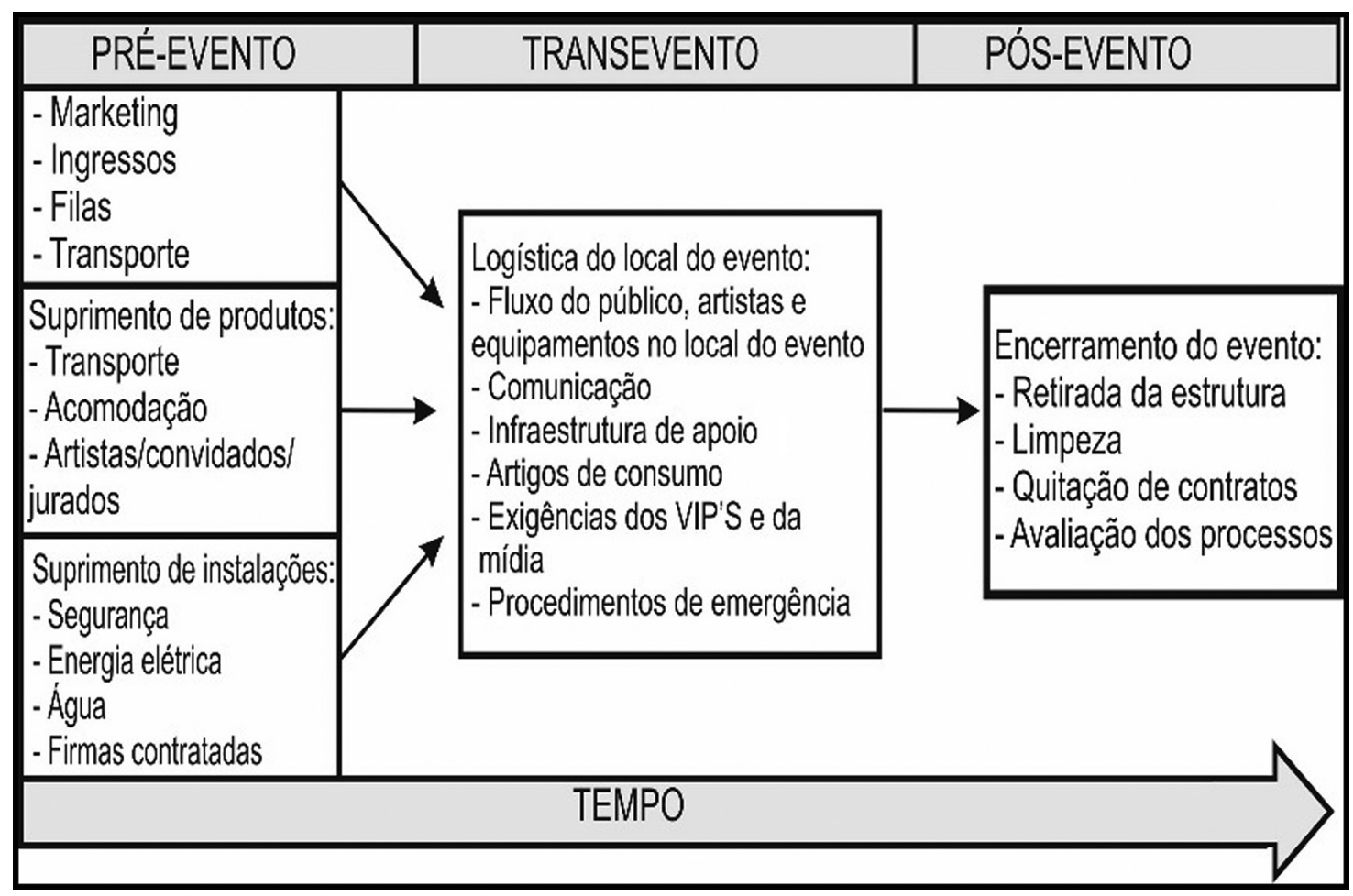

Figura 2. Os componentes das três fases de um evento. Fonte: Stock (2009). 
dos indivíduos juntamente com a interpretação do ambiente da problemática e, para tal, tende a ser menos estruturada e com atenção na interpretação subjetiva dos indivíduos e no entendimento dos processos que levam aos resultados (Cauchick Miguel, 2012). Segundo Triviños (2009), na pesquisa qualitativa, o ambiente natural é a fonte direta dos dados e o pesquisador é o instrumento-chave.

Para Flick (2004), é importante ressaltar que as ideias centrais que norteiam a pesquisa qualitativa são diferentes das encontradas na pesquisa quantitativa. Alguns aspectos devem ser considerados, como: a habilidade do pesquisador na escolha de métodos e teorias que se adequem ao objeto de estudo; a identificação e verificação das diferentes perspectivas; o reconhecimento por parte do pesquisador de que sua pesquisa faz parte de um processo de produção de conhecimentos e a diversificação na aplicação de técnicas e métodos.

O corte transversal é caracterizado pelo fato de pesquisar-se as práticas de distribuição prevalecentes no momento da realização da pesquisa, sem investigação das práticas passadas ou de sua evolução no tempo, o que caracterizaria um corte longitudinal. Os procedimentos técnicos usados foram estudo de caso exploratório e de fontes secundárias baseadas em livros, dissertações, teses, anais de congressos e artigos científicos que tratam do assunto (Cauchick Miguel, 2012).

As palavras-chave usadas na busca bibliográfica foram cadeia de valor, evento, megaevento, serviços, estudo de caso, atividade primária e atividade secundária. Elas foram usadas tanto em português quanto em inglês nas bases de dados Portal de periódicos da Capes, Scopus e Science Direct, sem restrição do período de publicação. Torna-se importante salientar que a pesquisa bibliográfica permeou toda a revisão da literatura já apresentada anteriormente, assim como a utilização do website do evento como ferramental de pesquisa complementar desta investigação.

O caráter exploratório permite a familiarização do problema com o intuito de torná-lo explícito, desenvolvendo um entendimento mais aprofundado do fenômeno analisado de forma flexível (Aaker et al., 2004). Neste tipo de pesquisa, é muito comum a utilização de dados e fontes secundárias (Dencker, 2007; Babbie, 2012). Dencker (2007) afirma que a pesquisa exploratória, além de permitir a flexibilidade do planejamento, envolve, em grande parte, levantamento bibliográfico, entrevistas com pessoas experientes e, quase sempre, apresenta-se como estudo de caso.

Escolheu-se fazer um estudo de caso para esta pesquisa de natureza empírica para desenvolver reflexões do tipo "por que" e "como" e por tratar-se de um fato contemporâneo, do qual os acadêmicos possuem pouco controle (Yin, 2008, 2010). Estudo de caso é um dos métodos mais relevantes na gestão de operações e é usado no detalhamento de problemas ainda não nitidamente estabelecidos (Voss et al., 2002). Ocorre quando o objeto de estudo ou tema abordado na investigação não permite que o pesquisador desenvolva hipóteses precisas e de fácil operacionalização dentro do seu contexto de vida real (Yin, 2010). Eisenhardt (1989) destaca que o estudo de caso torna viável a elucidação sobre temáticas que ainda não tiveram propostas de estudos mais aprofundados. O estudo de caso, nesta pesquisa, foi estruturado seguindo as etapas propostas por Cauchick Miguel (2007, 2012), conforme serão detalhadas a seguir, para minimizar as dificuldades na validação e as tendenciosidades deste método que é baseado nas percepções dos pesquisados. Permitiu-se, assim, maior confiabilidade para que este estudo possa ser mais tarde repetido exibindo os mesmos resultados.

Primeiramente trabalhou-se no nível estratégico da condução da investigação baseando-se nas questões e no objetivo de pesquisa, chegando-se à conclusão de que se iria fazer um estudo de caso único para se ter maior aprofundamento na investigação (Voss et al., 2002; Yin, 2008, 2010). Depois se trabalhou no nível operacional da condução da investigação, agrupando-se as seis etapas propostas por Cauchick Miguel (2007, 2012) duas a duas na seguinte sequência: "definição de uma estrutura conceitual-teórica e planejamento do caso", "condução de um teste-piloto e coleta dos dados" e "análise dos dados e geração do relatório da pesquisa".

\subsection{Definição de uma estrutura conceitual- teórica e planejamento do caso}

Delineou-se uma estrutura conceitual teórica mapeando a literatura. Procurou-se ver como as bibliografias já existentes enriquecem esta pesquisa e delinear o que será analisado conforme foi apresentado anteriormente.

Planejou-se o caso baseado em múltiplos métodos de coleta de dados, isto é triangulação (Yin, 2008, 2010); decidiu-se por fazer estudo com entrevistas semiestruturadas, análises documentais e observações diretas. Selecionou-se como unidade de análise a Feira de Negócios Agropecuários da Fronteira Oeste do Rio Grande do Sul - Fenaoeste.

A Fenaoeste é vista como a maior feira do gênero realizada na região. O evento é realizado anualmente, durante a primavera, período este considerado propício para a reprodução dos animais que participam da feira. Considerado um megaevento, a Fenaoeste concentra uma variedade de atividades, tais como: shows, exposição de bovinos e equinos, vendas de diversos tipos de equipamentos ligados à agropecuária, assim como os tradicionais leilões de animais, conhecidos na região como "remates". Segundo informado pelo secretário 
da presidência do evento, a última edição da feira, realizada no ano de 2012, reuniu aproximadamente 70 mil pessoas, teve um custo operacional de R \$ 1,3 milhões e movimentou aproximadamente $\mathrm{R} \$ 13$ milhões durante os nove dias de realização do evento (valor total movimentado na feira referente a vendas de maquinários, equipamentos, leilões de animais, aluguel de espaços e consumo de bebidas).

As entrevistas foram influenciadas pela literatura pesquisada. O protocolo para coleta dos dados não apenas delimitou um guia de entrevista, como também apontou ações e regras gerais da pesquisa para sua condução (Cauchick Miguel, 2007, 2012). Entretanto, procurou-se ao mesmo tempo manter flexibilidade para adicionar perguntas caso elas fossem necessárias de acordo com o entrevistado, permitindo-lhe opinar com total liberdade (Yin, 2008, 2010).

$\mathrm{Na}$ escolha dos entrevistados, levou-se em consideração a experiência e o tempo deles em megaeventos, procurando selecionar aqueles que estivessem no mínimo há três anos na Fenaoeste. Também se procurou um perfil variado em relação às áreas funcionais, posições hierárquicas, nível de escolaridade e gênero (Cauchick Miguel, 2007, 2012). Foram entrevistados o secretário geral da presidência do Sindicato Rural da cidade de São Borja e oito empresários que atuam como expositores no Parque de Exposições durante o evento.

Um questionário com 78 perguntas agrupadas de acordo com o modelo proposto no referencial teórico subsidiou esta etapa da pesquisa.

\subsection{Condução de um teste-piloto e coleta dos dados}

Um teste-piloto foi feito em um pequeno evento na mesma região, promovido por uma universidade para fazer os ajustes necessários antes de dar início à coleta de dados. Baseando-se nos ajustamentos obtidos com o teste-piloto, 18 perguntas foram fundidas entre si, 15 foram retiradas, cinco foram acrescentas e 20 modificadas; o questionário final passou a ter no total 57 perguntas para auxiliar na entrevista.

Antes de começar a coleta de dados, comunicou-se aos informantes que a pesquisa teria um caráter de confidencialidade dos pontos que eles desejassem e eles aceitaram ser entrevistados. Estipulou-se que as entrevistas deveriam levar em média não mais que quatro horas. $\mathrm{O}$ gravador não foi usado, pois poderia ter uma participação intrusiva, encabulando ou constrangendo os entrevistados. Portanto, usaram-se anotações no computador, ponderando as impressões e as observações dos entrevistadores. Os entrevistadores procuraram não influenciar os entrevistados; mantiveram a sua imparcialidade, não apresentando as suas opiniões, e compartilharam as suas anotações imediatamente após a entrevista com os entrevistados para que estes pudessem fazer eventuais modificações (Cauchick Miguel, 2007, 2012; Yin, 2008, 2010).

\subsection{Análise dos dados e geração do relatório da pesquisa}

$\mathrm{Na}$ etapa da análise de dados, o trabalho pautou-se principalmente no modelo de Porter (1999) com as modificações apresentadas anteriormente. Também se recorreu aos estudos de Allen et al. (2010), que serviram de subsídio para ilustrar as fases do planejamento de eventos. A análise também foi entregue aos entrevistados para poderem revisar e também foi verificada a sua consistência com as observações realizadas e os documentos consultados. Depois foi construído um painel demonstrativo para poder ter uma visão simultaneamente geral e detalhada dos dados e, com isto, diminuí-los, focando os dados que eram essenciais (Cauchick Miguel, 2007, 2012; Yin, 2008, 2010). Isto permitiu criar uma análise final, que será apresentada na próxima seção.

Criou-se um relatório que resumiu todas as atividades anteriores e ele foi também compartilhado com os entrevistados (Cauchick Miguel, 2007, 2012; Yin, 2008, 2010). Os entrevistados fizeram cópias do relatório e distribuíram-no entre os seus pares na Fenaoeste para ser usado na reunião de diretória durante o pré-evento. Os desdobramentos do relatório geraram também este artigo e materiais didáticos e de pesquisa para cursos de gestão e produção e de gestão de serviços, tanto para a graduação quanto para a pós-graduação.

\section{Análise da cadeia de valor da Fenaoeste}

A análise da cadeia de valor da Fenaoeste baseou-se no modelo proposto por Porter (1999) com algumas modificações, seguindo as escolhas das atividades feitas por Barbosa (2010), conforme apresentado anteriormente. Utilizaram-se do modelo de Porter (1999) algumas das atividades do constructo atividades de apoio ("infraestrutura", "recursos humanos", "administração" e "tecnologia da informação"), juntamente com a integração das atividades do constructo atividades primárias em dois grupos ("logística operacional" e "marketing e pós-venda").

\subsection{Atividades de apoio}

Segundo Porter (1999), as atividades de apoio são as que sustentam as atividades primárias, fornecendo recursos para que elas exerçam suas funções dentro da cadeia de valor. 


\subsubsection{Infraestrutura}

A Fenaoeste é um megaevento que movimenta a cidade de São Borja, assim como a região da fronteira oeste do Rio Grande do Sul, durante os nove dias em que acontece. Desde o ano de 2011, ganhou o status de feira internacional por atrair expositores de diversos países além do Brasil, tais como: Argentina, Uruguai, Peru e Chile. O evento é uma realização do Sindicato Rural da Cidade de São Borja, em parceria como a Prefeitura Municipal de São Borja e a Associação Comercial e Industrial de São Borja - ACISB, instituições que participam do evento como organizadoras. O evento é realizado no Parque de Exposições Serafim Dornelles Vargas, espaço com o tamanho equivalente a 68 hectares. Contudo, o evento ocupa apenas 25 hectares deste espaço. O Parque de Exposições possui pista de rodeio e alojamentos para os "cabanheiros" (vocábulo regional utilizado para denominar expositores) que vêm à feira para participar da exposição de animais, abriga também o núcleo de criadores de cavalos crioulos e a sede administrativa do Sindicato Rural de São Borja, além de possuir espaços estruturados para abrigar os animais que são expostos no evento.

O planejamento do evento é realizado com quase um ano de antecedência, ou seja, praticamente quando se encerra uma edição, a organização da Fenaoeste já está se preparando para a próxima. A equipe que participa da organização do evento é composta pelo presidente do Sindicato Rural e pelos diretores das comissões que são formadas durante a fase do pré-evento. No total, são cinco comissões: infraestrutura, segurança, pecuária, recepção e divulgação. Cada comissão possui dois diretores, que possuem a responsabilidade de estruturar as demandas que a feira necessita para serem introduzidas da melhor forma possível.

Com relação ao planejamento financeiro do evento, os entrevistados salientaram que é realizada uma estimativa de receita com base no que foi arrecadado no ano anterior. Grande parte da receita da Fenaoeste vem dos contratos de patrocínios firmados durante as fases de pré-evento e transevento, das comissões recebidas por ocasião dos remates, da utilização da Lei Rouanet de incentivo à cultura e da venda de espaços para os expositores e comerciantes locais que participam de toda a programação do evento. Os entrevistados explicaram ainda que a feira possui um apoio jurídico responsável por assessorar principalmente os contratos que são firmados durante os preparativos do evento.

Também foi salientada pelos entrevistados a importância do registro da feira junto à Secretaria de Agricultura. Segundo os entrevistados, este procedimento colabora para que os animais envolvidos participem da feira em total segurança. O registro da feira como um evento oficial do setor agropecuário também contribui para que as negociações realizadas junto às instituições bancárias sejam efetivadas de forma mais rápida e com taxas de juros reduzidas. Para os entrevistados, o sucesso da feira se deve ao fato de que o Sindicato Rural de São Borja está sempre investindo e reinvestindo na infraestrutura do evento. Alguns exemplos referentes a estes investimentos são: R \$ 180 mil, recentemente investidos na estrutura móvel do Parque de Exposições, e R 15 mil, investidos na estrutura das mangueiras que abrigam os animais que participam da exposição e na compra de um gerador de energia que atende a toda a área do parque onde se realiza o evento.

\subsubsection{Recursos humanos}

A organização da Fenaoeste terceiriza alguns profissionais para desenvolver atividades específicas durante o pré-evento e o transevento. Os profissionais que não são contratados executam tarefas ligadas à promoção e divulgação do evento, venda de espaços, assessoria aos interessados em participar da exposição, emissão e impressão de boletos, cobrança, entrega de credenciais e outras atividades de apoio. A organização da feira também contrata profissionais para fazer a divulgação do evento em cidades próximas a São Borja. Os entrevistados explicaram que esta divulgação específica tem como público alvo os "cabanheiros" da região. Faz parte dos profissionais terceirizados do evento uma equipe de aproximadamente 150 seguranças pertencentes ao quadro funcional de duas empresas, os profissionais envolvidos na limpeza do parque e a equipe de trabalho que atua durante os dias de realização da feira fazendo o trabalho de recepção, vendas e validação dos ingressos na bilheteria.

\subsubsection{Administração}

A equipe gestora da Fenaoeste basicamente é composta pelo presidente do Sindicato Rural de São Borja, pelos dois vice-presidentes, pelos dois secretários e pelo tesoureiro. Segundo os entrevistados, os procedimentos relacionados às compras do evento passam diretamente pela responsabilidade dos diretores das comissões. Cada responsável faz um levantamento das necessidades da sua comissão e encaminha-o ao presidente do Sindicato Rural para que a solicitação seja aprovada. Depois da aprovação do pedido, é realizada uma pesquisa de preços pela secretaria do Sindicato e, então, é efetivada a compra. Segundo os entrevistados, o Sindicato Rural possui um caixa para pagamento de despesas consideradas importantes para o bom andamento das atividades do evento.

\subsubsection{Tecnologia da informação}

Com relação aos procedimentos atrelados à tecnologia da informação, os entrevistados consideram-nos 
indispensáveis. Explicaram que os recursos tecnológicos assumiram um papel de extrema relevância dentro do evento, pois, além das vendas realizadas por meio da internet pela empresa contratada pela feira, todos os procedimentos de validação e reconhecimento dos ingressos na bilheteria do evento são informatizados. Os entrevistados explicaram que as vendas pelo sistema eletrônico da empresa contratada possibilitam que, a qualquer momento e em qualquer local, possa verificar-se o andamento das vendas. Desta forma, torna-se possível verificar os locais com menos quantidade de ingressos vendidos e, assim, massificar a comunicação do evento.

Os entrevistados explicaram que existem alguns procedimentos que ainda são realizados manualmente, principalmente os relacionados às inscrições dos animais em exposição na feira. Este procedimento, segundo os entrevistados, são atividades que necessitam ser realizadas manualmente e da qual participam um veterinário e um zootecnista.

\subsection{Atividades primárias}

\subsubsection{Logística operacional}

Com relação aos procedimentos de logística operacional da Fenaoeste, os entrevistados explicaram que a organização adota alguns critérios para determiná-los. A manutenção da infraestrutura do Parque de Exposições é uma das maiores preocupações da equipe de organização da feira. Para que tudo esteja a contento, as visitas ao local do evento para verificação dos ajustes necessários são iniciadas com aproximadamente seis meses de antecedência. Outra preocupação da organização é com a locação da infraestrutura móvel (palco, sonorização e iluminação). Segundo os entrevistados, caso os contratos destes serviços não sejam firmados com antecedência, o evento acaba correndo dois riscos: o primeiro é de não conseguir prestadores de serviços para a época desejada e o outro é de pagar bem mais caro por não ter realizado um prévio planejamento.

Os entrevistados explicaram que os shows durante a feira passaram a ser um dos grandes atrativos. A sua realização possibilitou um investimento maior na divulgação da feira, impulsionando diretamente a quantidade de negócios realizados durante o evento. De acordo com os entrevistados, três aspectos são levados em conta quando da escolha dos artistas para participarem da feira: o momento em que o artista se encontra na mídia nacional, a agenda e a possibilidade de conciliar os shows do artista com outros eventos da região. Esta estratégia facilita a logística de transporte de equipamentos montada para atender ao evento e também minimiza os valores para os contratantes.
Outro aspecto interessante verificado durante a pesquisa com relação à logística operacional está ligado diretamente às atividades durante a feira. Os entrevistados explicaram que com uma semana de antecedência à feira é realizada uma reunião com todos os participantes, para que sejam determinadas as regras de acesso ao evento por parte de expositores, "cabanheiros" e participantes. Estas regras são fundamentais para que a organização alcance os objetivos planejados.

\subsubsection{Marketing e pós-vendas}

Com relação à promoção da Fenaoeste, o evento possui um planejamento estratégico de marketing que tem como principais ferramentas de comunicação: website da empresa contratada para comercialização dos ingressos, televisão, rádio, jornal, material promocional impresso (distribuído em todos os Sindicatos Rurais do Estado do Rio Grande do Sul). Além do mais, há uma forte divulgação da feira na Expointer, que é a maior feira do segmento Agropecuário da América Latina (Expointer, 2013). Os entrevistados explicaram que o evento trabalha com canais de distribuição de modalidade direta e indireta. Aproximadamente 5\% dos ingressos são vendidos via website do evento, $80 \%$ vendidos nos pontos de vendas autorizados e $15 \%$ dos ingressos são comercializados na bilheteria.

Com relação às atividades de pós-vendas, a organização da Fenaoeste aplica questionários de avaliação junto aos participantes da feira com o objetivo de sanar eventuais falhas apresentadas naquela edição. Também é realizada uma pesquisa de opinião junto aos expositores que participam da feira independentemente do porte. Neste documento, cada expositor também informa quanto foi o seu faturamento durante o evento. Estes dados servem para que a organização tenha uma noção do total de receitas geradas pela feira. Posteriormente cada expositor recebe um documento do Sindicato Rural com um pequeno balanço da feira. Aos colaboradores ACISB e Prefeitura Municipal, o Sindicato envia um balanço com números mais detalhados.

\section{Questões estratégicas}

Montou-se a Figura 3 e a Figura 4 com as questões compreendidas pelos entrevistados como estratégicas de competitividade para, respectivamente, as atividades de apoio e as atividades primárias da Fenaoeste.

A infraestrutura da Fenaoeste foi avaliada como atendendo às necessidades do evento e não apresentando problemas. Considerou-se que o parque de exposições Serafim Dornelles Vargas possui características que vão ao encontro das necessidades e objetivos da organização da feira. A pesquisa também apontou uma grande preocupação por parte da equipe de gestão do evento em conservar o parque em perfeitas 


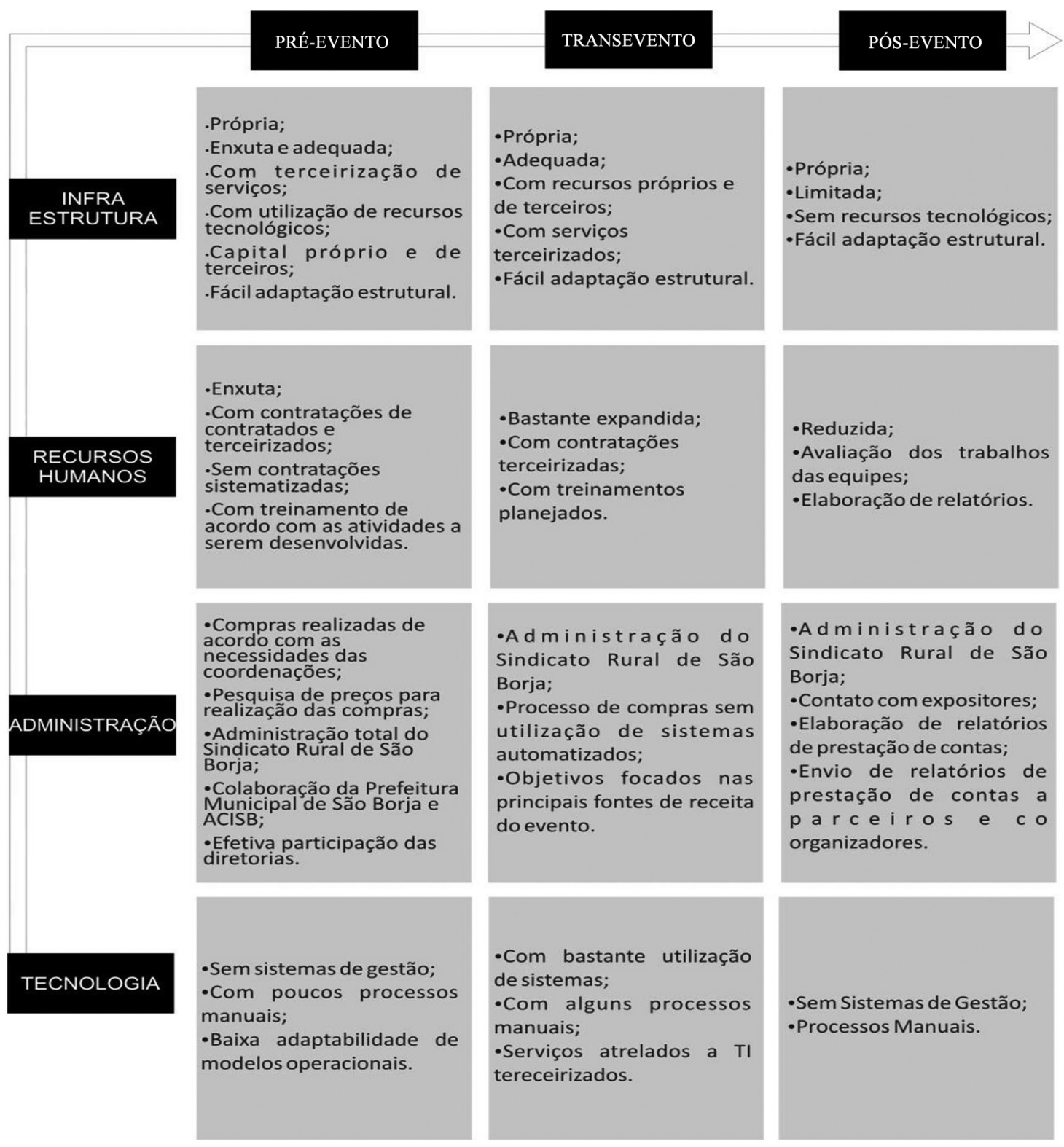

Figura 3. Atividades de apoio da Fenaoste. Fonte: elaborado pelos autores.

condições de funcionamento, evitando-se retrabalho que, além de consumir tempo e dinheiro, compromete a qualidade dos serviços oferecidos.

Com relação aos processos de terceirização dos serviços que são oferecidos durante a realização da feira, entende-se sua viabilidade em função de que não existe a necessidade de manter uma grande quantidade de profissionais vinculados ao Sindicato Rural de São Borja, uma vez que eles só teriam atividades durante o período de planejamento e implementação do evento. Dentre os principais serviços terceirizados pela Fenaoeste encontram-se: os serviços de recepção, segurança, sonorização, infraestrutura, móveis e limpeza.
A parte administrativa ficou responsável pelas compras e conta com a acentuada cooperação das diretorias. Ela mantém o foco nos pontos de maior fonte de renda do evento. Possui intensa interação com os expositores, a prefeitura e os organizadores.

A tecnologia da informação foi apontada como uma das mais importantes atividades durante o processo de planejamento e implementação da feira. Os recursos tecnológicos representados pelos sistemas eletrônicos de vendas realizam vendas de bilhetes, emitem relatórios em tempo real e também são utilizados nas catracas de acesso ao parque de exposições, fazendo validação dos ingressos e reconhecimento, via fotografia do portador, garantindo segurança e agilidade nas atividades de acesso ao parque. 


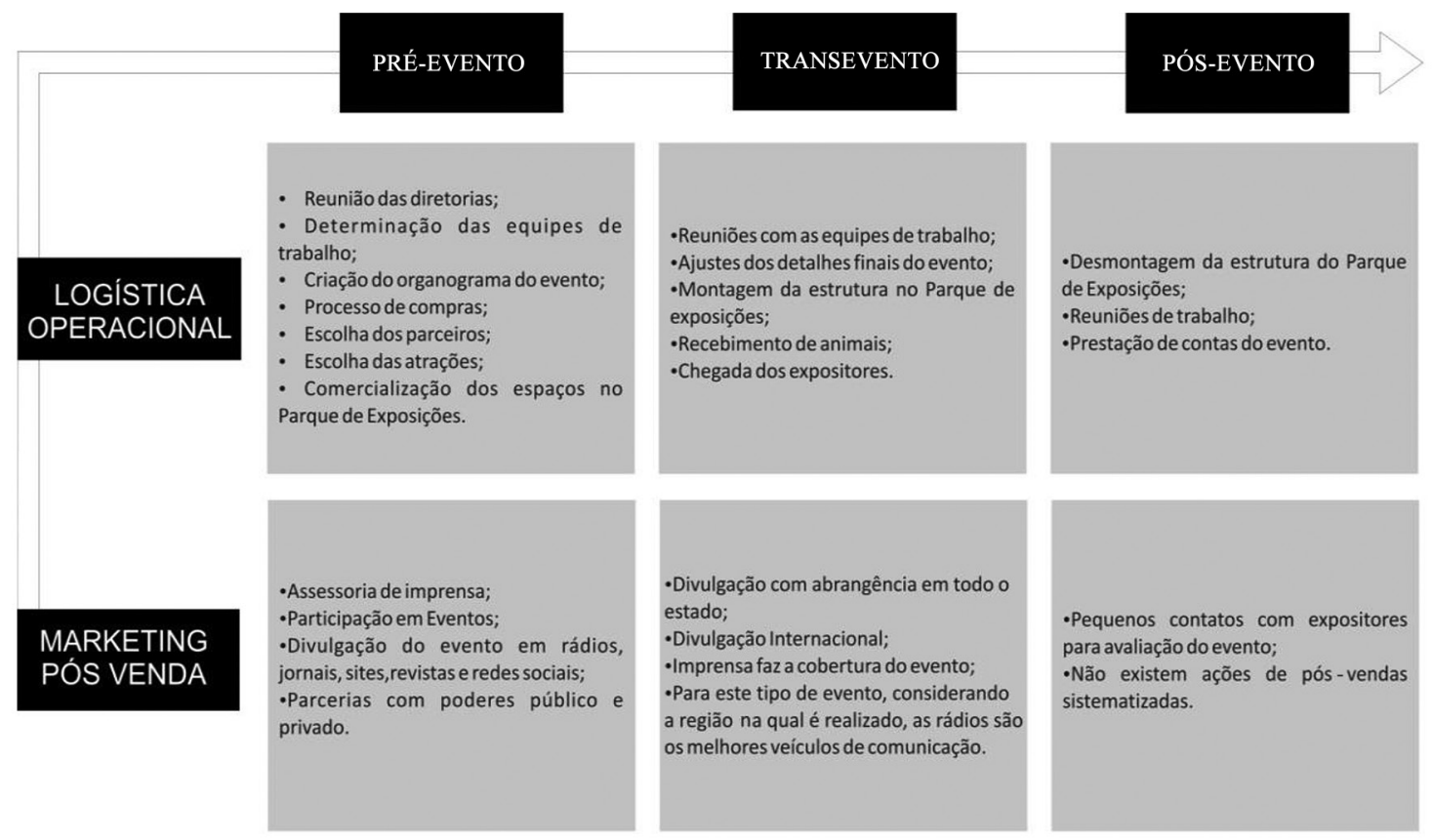

Figura 4. Atividades primárias da Fenaoeste. Fonte: elaborado pelos autores.

Tanto as questões ligadas às atividades de logística operacional quanto as ligadas às atividades de marketing e pós-venda enfatizaram a importância dos clientes internos e dos clientes externos nos processos. As atividades de marketing e pós-venda focaram divulgar a programação do evento estimulando ambos os clientes externos e internos a participarem e tentando coletar informações destes clientes para desenvolvimento e planejamento do evento presente e também das versões futuras do próprio evento.

Os canais de comunicação tradicionais e eletrônicos têm grande influência nas atividades de marketing e pós-venda, sendo que os eletrônicos têm forte tendência de crescimento. Uma peculiaridade verificada durante a pesquisa está diretamente ligada às ações de pós-vendas. A organização do evento realiza ações de pós-vendas com os expositores da feira que, além de ratificar a parceria para as próximas edições do evento, apresentam um breve balanço dos números alcançados.

\section{Conclusão, limitações e pesquisas futuras}

Esta investigação teve como objetivo analisar os megaeventos utilizando o mapeamento das atividades de apoio e das atividades primárias que compõem a cadeia de valor do evento por meio do estudo de caso da Fenaoeste de São Borja/RS. Fez-se a pesquisa baseada na cadeia de valor de Porter (1999) com algumas modificações para adequar a sua aplicação às perspectivas de serviços. A metodologia contemplou o referencial teórico e analisou a dinâmica do megaevento Fenaoeste por meio de entrevistas. Pretende-se agora desenvolver algumas reflexões sobre as especificidades desta cadeia de valor para auxiliar na sua melhoria.

$\mathrm{O}$ estudo de megaeventos é oportuno para o amadurecimento da análise da cadeia de valor em serviços por tratar-se de um serviço que tem fortemente presente a experiência do cliente como produto, situando o estudo ao longo do espectro de serviços-manufatura, em que, em um extremo, se tem os serviços "puros" e, no outro extremo, se tem manufatura "pura", perto do extremo de serviços "puros". Isto auxilia o estudo dos aspectos de gestão de serviços a identificar suas particularidades nas decisões estratégicas na busca de vantagens competitivas. Estes serviços estão entrelaçados em ações coordenadas que resultarão em um evento.

Podem-se sublinhar alguns pontos obtidos ao longo do estudo de caso. A infraestrutura tecnológica e os clientes (tanto internos quanto externos) têm grande influência no funcionamento das atividades primárias e de apoio. Os clientes internos e externos vão além dos respectivos tradicionais funcionários e clientes finais. Os clientes também são a prefeitura (governo) e as associações comerciais e industriais que participam do evento como organizadores, faltando apenas a universidade para ter-se o trio governo-indústria-universidade. A universidade poderia ser importante na preparação dos funcionários e estudos dos usuários finais, sendo a sua cooperação oportuna por tratar-se de um local que está se transformando em um grande polo educacional. 
A possibilidade de ligação da universidade se enfatiza pelo evento caracterizar-se por seus aspectos de promoções culturais, recebendo incentivos legais à cultura. Também são requeridos tecnologias e conhecimentos específicos em que a universidade poderia ajudar, por exemplo: auxílio jurídico na preparação dos contratos, registro e segurança dos animais segundo a literatura veterinária e monitoramento das formas e locais de vendas dos bilhetes para poder definir as estratégias de gestão dos eventos. A melhoria na gestão do evento poderia contribuir no uso da capacidade do espaço, que atualmente ocupa um pouco mais de um terço de sua capacidade total, possuindo, assim, oportunidade de crescimento. A estimativa da receita é calculada basicamente apenas no ganho do ano anterior, por causa do pouco uso de sistemas de gestão principalmente nos pré-eventos e da pequena preocupação de se calcular os valores intangíveis. Portanto, o conhecimento promovido pela universidade poderia sofisticar mais os sistemas de gestão e orientar os seus usos.

Muitos eventos, como este, ocorrem com baixas frequências, tornando a sua gestão mais complexa, uma vez que a falha em um dia de funcionamento tem um grande impacto no evento como um todo. Observou-se que, durante quase o ano inteiro, alguns clientes internos ficam preparando o evento, o que leva a crer que se deva melhorar a eficiência na sua preparação e fazer maior gestão de sua sazonalidade também.

Existe um forte aspecto de intangibilidade. Quase todos os bens são terceirizados, principalmente para evitar-se deixá-los ociosos por causa do longo período de não funcionamento. Até mesmo muitos funcionários que atuam apenas durante o transevento começaram a ser terceirizados, sendo esta uma prática delicada, pois pode atrapalhar a qualidade dos serviços prestados. Para minimizar o impacto na qualidade dos serviços, que é fundamental para o evento, deve-se procurar apenas terceirizar os funcionários que têm funções vistas como menos estratégicas.

A simultaneidade, característica típica de serviços, está fortemente presente não apenas entre a produção e o consumo, mas em todas as etapas do evento. O pós-evento pode ser entendido como uma logística reversa que influencia diretamente o pré-evento e, com isto, o cliente até participa da concepção do evento, que pode ser julgada como parte do produto, juntamente com o desenvolvimento e o consumo. A perecibilidade está relacionada à simultaneidade do evento. Na medida em que as etapas do evento ocorrem ao mesmo tempo da participação do cliente, que passa a ser um coprodutor, dificulta-se o armazenado dos serviços, principalmente porque no caso dos eventos estes serviços são caracterizados pelas experiências obtidas pelos clientes. Como os clientes atuam como coprodutores, passa-se a ter a necessidade de definições de regras de atuação dos clientes. Estas regras devem ser simples para evitar-se o risco de perder o cliente para a concorrência; isto serve tanto para o cliente externo, quanto para o cliente interno.

Os eventos são fortemente dependentes dos seus shows que acentuam mais ainda os aspectos de simultaneidade e de perecibilidade. Torna-se necessário gerenciar os riscos de não se conseguir os clientes internos e externos ao longo de todas as atividades primárias da cadeia de valor. Deve-se procurar fazer esta gestão com antecedência para minimizar os custos envolvidos de contratações de último momento. Os canais tradicionais e eletrônicos de divulgação auxiliam esta gestão que influencia as atividades de logística operacional e de marketing e pós-vendas de forma tal que cada uma delas acaba por interferir na outra, como um ciclo fechado entre elas.

Como esperado por Barbosa (2013), os suprimentos (também conhecidos por compras ou também por aquisições) não se apresentam como atividades de apoio da cadeia de valor dos eventos. Elas estão inseridas na administração e são de responsabilidade dos diretores das comissões que se baseiam em um processo sem utilização de sistemas automatizados. Isto reforça que a preocupação maior da gestão não está estrategicamente na aquisição de bens, mas sim no desenvolvimento dos aspectos intangíveis dos eventos. Isto se reflete na subjetividade da gestão e, consequentemente, na complexidade do uso e desenvolvimento da tecnologia de informação.

Os procedimentos operacionais se encontram intensamente automatizados, como é o caso dos reconhecimentos dos bilhetes na entrada dos eventos que já são $100 \%$ informatizados. Mas as etapas que envolvem mais a necessidade da interação humana (com os clientes) e usos de conhecimento, que, no caso dos eventos, são normalmente as etapas estratégicas, precisam ser mais informatizadas, pois muitas ainda são manuais, apresentando pouca agilidade. De forma simplificada, pode-se dizer que as tecnologias de informação neste evento são menos usadas quando se trata do pós-evento, em que se tem uma forte presença dos métodos manuais. Aplica-se pouco o meio eletrônico nas pesquisas de opiniões e avaliações dos clientes.

O evento possui um bom nível de treinamento dos funcionários que poderia ser aprimorado com o uso de um banco de dados melhor, proveniente destas pesquisas de opiniões e avaliações dos clientes. Os procedimentos já informatizados podem servir de fontes de dados que auxiliem na gestão dos procedimentos menos informatizados. Portanto, é benéfica a integração de ambos os procedimentos, fazendo um equilíbrio do high-tech com o high-touch. Práticas como gestão de rendimento ainda são pouco empregadas. A gestão de rendimento poderia diminuir o risco da variabilidade 
do número de clientes esperados, maximizar o quanto cada um dos clientes poderia pagar, oferecendo-lhes serviços diferenciados de acordo com a segmentação dos próprios clientes.

A cadeia de valor de megaeventos ainda não se consolidou como um grande tema explorado pela comunidade acadêmica, o que possibilita que novas pesquisas sejam realizadas, assim, talvez, novos modelos para análises possam ser apresentados. O segmento de megaeventos em particular, por possuir uma dinâmica diferenciada de outros serviços, necessita de uma adaptação de um modelo de cadeia de valor para que este corresponda às peculiaridades do segmento. Isto ocorre pelo fato de que os modelos propostos para bens de consumo já possuem teorias clássicas que são aplicadas em sua gestão da cadeia de valor, enquanto que os serviços tentam se adequar às teorias já existentes.

Cada vez mais, atividades vêm sendo adotadas fora da cadeia de valor do evento e ao longo de sua cadeia de suprimentos. Por exemplo, a grande maioria dos ingressos não é vendida no evento (incluindo os seus sites), mas sim em pontos de vendas autorizadas. Até mesmo eventos concorrentes (incluindo eventos no exterior) podem fazer parte da cadeia de suprimentos, desservindo como benchmarking ou lugar de divulgação.

O segmento de megaeventos, por apresentar um grande crescimento e uma exigência pela demanda por qualidade, necessitará cada vez mais de profissionais qualificados. Este segmento tende a ser uma das grandes áreas a empregar profissionais até o ano de 2016 no Brasil, dada a realização de dois megaeventos no país: a Copa do Mundo de 2014 e as Olimpíadas de 2016. Estes acontecimentos exigem profissionais que entendam a dinâmica do setor e que saibam administrar os seus respectivos processos.

Vale sublinhar que esta pesquisa não é final. $\mathrm{O}$ estudo possui algumas limitações que podem ser minimizadas com pesquisas futuras. A análise desta pesquisa é baseada apenas em um estudo de caso único. O estudo de caso per se já apresenta algumas limitações como: dificuldades em validar os resultados, análises baseadas em percepções dos pesquisados e complicações em interpretar os dados (Cauchick Miguel, 2012).

$\mathrm{O}$ fato de ser caso único adiciona mais outras limitações, principalmente em como generalizar o estudo. Tem-se o perigo de realizar uma avaliação inapropriada já que se trata de apenas um acontecimento singular, o que, consequentemente, traz desconfianças da possibilidade de poder ocorrer em outras situações. Para enfrentar estas limitações, normalmente se usam estrategicamente estudos como exploratórios (como foi esta pesquisa), reveladores (como os casos raros e novos) e longitudinais (Cauchick Miguel, 2012). Também se entrevistaram apenas nove pessoas. Seria interessante ampliar o número de entrevistados e desenvolver-se uma pesquisa com estudo de casos múltiplos, replicando as modificações propostas para a cadeia de valor de Porter (1999) para conseguir maior grau de generalização dos resultados.

O estudo apresentado ocorre em uma cidade do interior e analisa a feira agropecuária. Outras análises poderiam ser feitas em maiores centros populacionais. O evento analisado tem a sua execução durante nove dias. Estudos futuros poderiam tratar de eventos de maior duração e de eventos que ocorrem ao longo de todo o ano. Esta pesquisa baseou-se em uma modificação da cadeia de valor tanto nas atividades primárias quanto nas atividades de apoio. Próximas pesquisas podem remover estas simplificações para analisar as atividades originais propostas por Porter (1999) e compará-las com esta pesquisa.

A análise feita representa a realidade brasileira, na qual se tem forte cultura latina, que influencia os tipos de relacionamentos entre as pessoas, e também integra a cultura germânica, por ter sido realizada em um estado brasileiro, Rio Grande do Sul, que tem forte presença alemã também. Mesmo assim, como se observou na pesquisa, em eventos, as pessoas (clientes internos e externos) têm influências nos desenvolvimentos das atividades primárias e de apoio, portanto, estudos com outros tipos de cultura poderiam enriquecer a análise feita. Por tratar-se também do Brasil, as questões encontradas neste país podem ser diferentes em países que tenham melhores (ou piores) infraestruturas tecnológicas, que, como também se percebeu nesta pesquisa, têm intenso impacto nos eventos. Seria benéfico realizar esta pesquisa em regiões e países com outras culturas e infraestruturas tecnológicas.

Sugere-se que novos estudos relacionados a esta temática sejam realizados, valendo-se de outros eventos de igual ou maior porte como objetos de estudo para ajudar a generalizar esta pesquisa. Pode-se também estudar outros tipos de serviços. Com o amadurecimento destas pesquisas, valeria estudar serviços não apenas próximos à extremidade de serviços "puros" no espectro serviços-manufatura; isto facilitará o desenvolvimento de uma análise mais equilibrada entre serviços e manufatura, uma vez que quase sempre na realidade os dois estão presentes juntos.

Espera-se que este trabalho venha contribuir para o desenvolvimento deste e de outros megaeventos e que eles se consolidem como propulsores do turismo de eventos nas suas respectivas regiões. Acredita-se que, com a crescente terceirização na Fenaoeste de aspectos gerenciais na busca da focalização nas suas principais competências, serão depois necessários estudos da sua cadeia de suprimentos. Trabalhos futuros, a partir da análise da cadeia de valor da Fenaoeste, baseados na expansão deste artigo ao longo da sua 
cadeia de suprimentos, podem contribuir para melhor entendimento da gestão da cadeia de suprimentos da Fenaoeste e de megaeventos em geral.

Recentemente o conceito de cadeia de valor foi ampliado mais ainda para o conceito de valor compartilhado (Porter \& Kramer, 2011). Este novo conceito ainda está na sua infância e tem uma visão de longo prazo. Ele se concentra não apenas em questões de negócios, mas também em questões sociais, por isto, tanto as empresas quanto a sociedade são beneficiadas. Neste conceito, as questões sociais e de negócios são vistas como essenciais e, portanto, têm que ocorrer simultaneamente para gerarem o valor compartilhado. Porter \& Kramer (2011) mencionam que a atenção agora está voltada aos países como Brasil para o desenvolvimento deste conceito. Sendo assim, também seria oportuno estender esta análise feita no Brasil para uma investigação mais ampla baseada no conceito de valor compartilhado tanto no Brasil como também em países similares.

\section{Referências}

Aaker, D. A., Kumar, V., \& Day, G. S. (2004). Pesquisa de marketing (2 ed.). São Paulo: Atlas.

Albrecht, K., \& Zemke, R. (1985). Service America. Homewood: Dow Jones-Irwin.

Allen, J., O’Toole, W., \& McDonald, I. (2010). Organização e gestão de eventos (3 ed.). Rio de Janeiro: Campus.

Anjos, S. J. G., Anjos, F. A., Silva, O. F. P., Jr. (2008). A informação como vantagem competitiva no processo logístico integrado nos serviços turísticos. Encontros Bibli: Revista Eletrônica de Biblioteconomia e Ciência da Informação, 13, 41-56.

Arasti, M. R., \& Moghaddam, N. B. (2010). Use of technology mapping in identification of fuel cell sub-technologies. International Journal of Hydrogen Energy, 35(17), 9516-9525. http://dx.doi.org/10.1016/j. ijhydene.2010.05.071.

Armistead, C. G, \& Clarck, G. (1993). Resource activity mapping: the value chain in service operations strategy. Service Industries Journal, 13(4), 221-239. http://dx.doi. org/10.1080/02642069300000070.

Associação Brasileira de Empresas de Eventos. (2012). WTTC: Brasil deve crescer turismo em 7,8\%. Recuperado em 29 de março de 2012, de http://www.abeoc.org. br/2012/03/wttc-brasil-deve-crescer-turismo-em-78/

Babbie, E. R. (2012). The practice of social research (13 ed.). Belmont: Wadsworth Publishing Company.

Ballou, R. H. (2006). Gerenciamento da cadeia de suprimentos: planejamento, organização e logística empresarial (5 ed.). Porto Alegre: Bookman.
Banco Central do Brasil. (2013). Economia e finanças. Recuperado em 30 de setembro de 2013, de http:// www.bcb.gov.br/?ECONOMIA

Barbosa, F. S. (2010). O processo logístico de eventos: um estudo de caso da Oktoberfest de Blumenau - SC. (Dissertação de mestrado). Universidade do Vale do Itajaí, Balneário Camboriú.

Barbosa, F. S. (2013). Planejamento estratégico para eventos: um estudo de caso das estratégias de marketing utilizadas pela Oktoberfest de Santa Cruz do Sul/RS. Cultur, 7(14), 87-104.

Bharati, P., \& Chaudhury, A. (2012). Technology assimilation across the value chain: an empirical study of small and medium-sized enterprises. Information Resources Management Journal, 25(1), 38-60. http://dx.doi. org/10.4018/irmj.2012010103.

Bitner, M. J., \& Brown, S. W. (2008). The service imperative. Business Horizons, 51(1), 39-46. http:// dx.doi.org/10.1016/j.bushor.2007.09.003.

Bovet, D., \& Martha, J. (2000). Value nets: reinventing the rusty supply chain of competitive advantage. Strategy \& Leadership, Bingley, 28(4), 21-26. http://dx.doi. org/10.1108/10878570010378654.

Bowersox, D. J., Closs, D. J., \& Cooper, M. B. (2014). Gestão logística de cadeia de suprimentos (4 ed.). Porto Alegre: Bookman.

Brasil. Ministério do Turismo. (2013). Estatísticas básicas de turismo. Recuperado em 24 de fevereiro de 2013, de http://www.dadosefatos.turismo.gov.br/dadosefatos/ estatisticas_indicadores/estatisticas_basicas_turismo

Britto, J., \& Fontes, N. (2004). Estratégias para eventos: uma ótica do marketing e do turismo. São Paulo: Aleph.

Butler, C., Bassiouni, Y., El-Adly, M., \& Widjaja, A. (2007). Revamping the value chain in exhibition facilities: the case of the Dubai exhibition industry. Facilities, 25(11/12), 419-436. http://dx.doi.org/10.1108/02632770710822544.

Cauchick Miguel, P. A. (2007). Estudo de caso na engenharia de produção: estruturação e recomendações para sua condução. Produção, 17(1), 216-229.

Cauchick Miguel, P. A. (Org.). (2012). Metodologia de pesquisa em engenharia de produção e gestão de operações. (2 ed.). Rio de Janeiro: Elsevier.

Christopher, M. (2011). Logística e gerenciamento da cadeia de suprimentos. São Paulo: Pioneira Thomson Learning.

Cooper, C., Fletcher, J., \& Wanhill, S. (2007). Turismo: princípios e práticas (3 ed.). Porto Alegre: Bookman.

Correa, H. L., Ellram, L. M., Scavarda, A. J, \& Cooper, M. C. (2007). An operations management view of the services and goods offering mix. International Journal of Operations and Production Management, 27(5), 444463. http://dx.doi.org/10.1108/01443570710742357. 
David, J., \& Prosch, M. (2010). Extending the value chain to incorporate privacy by design principles. Identity in the Information Society, 3(2), 295-318.

De Conto, S. M., Britto, J. C., \& Schnorrenberger, A. (2013). Proposta de modelo de cadeia de valor para um centro universitário. Revista Gestão Universitária na América Latina: Revista GUAL, 6(2), 143-159.

Dehning, B., Richardson, V. J., \& Zmud, R. W. (2007). The financial performance effects of it-based supply chain management systems in manufacturing firms. Journal of Operations Management, Amsterdam, 25(4), 806-824. http://dx.doi.org/10.1016/j.jom.2006.09.001.

Dencker, A. F. M. (2007). Métodos e técnicas de pesquisa em turismo (9 ed.). São Paulo: Futura.

Díaz-Peña, L. C., Chavez-Capo, A. S., Tinoco-Castrejón, M. A., Rosano-Ortega, G., \& Pérez-Armendariz, B. (2013). Financial assessment of a biodiesel value chain: case study of Chiapas, Mexico. Management Research Review, 36(12), 1291-1302. http://dx.doi.org/10.1108/ mrr-08-2013-0196.

Edgington, D. W., \& Hayter, R. (2013). In situ dynamics of Japanese electronic subsidiaries in ASEAN countries: Reflections from a development perspective. Asia Pacific Viewpoint, 54(1), 15-32.

Eisenhardt, K. M. (1989). Building Theories from case study research. Academy of Management, 14(4), 532-550.

El-Akruti, K., Dwight, R., \& Zhang, T. L. (2013). The strategic role of engineering asset management. International Journal of Production Economics, Amsterdam, 146(1), 227-239. http://dx.doi.org/10.1016/j.ijpe.2013.07.002.

Expointer.(2013). Exposição Internacional. Recuperada em 5 de maio de 2013, de http://www.expointer.rs.gov. br/site2012/conteudo/1556/?N\%C3\%BAmeros_finais_ consolidam_Expointer_como_a_maior_feira_da Agropecu\%C3\%A1ria_latino_americana

Fitzsimmons, J. A., \& Fitzsimmons, M. J. (2014). Administração de serviços: operações, estratégia e tecnologia da informação (7 ed.). Porto Alegre: Bookman.

Flick, U. (2004). Uma introdução à pesquisa qualitativa ( 2 ed.). Porto Alegre: Bookman.

Getz, D. (1993). Festivals and special events. In M. A. Khan, M. D. Olsen, \& T. Var (Eds.), Encyclopedia of hospitality and tourism (pp. 789-810). New York: Van Nostrand Reinhold.

Goeldner, C. R., Ritchie, J. R. B., \& McIntosh, R. W. (2002). Turismo: princípios, práticas e filosofias $(8$ ed.). Porto Alegre: Bookman.

Gorla, N., Somers, T. M., \& Wong, B. (2010). Organizational impact of system quality, information quality, and service quality. Journal of Strategic Information Systems, 19(3), 207-228. http://dx.doi.org/10.1016/j.jsis.2010.05.001.

Gummesson, E. (1991). Service management an evaluation and the future. International Journal of Service
Industry Management, 5(1), 77-96. http://dx.doi. org/10.1108/09564239410051920.

Gwebu, K. L., Wang, J., \& Wang, L. (2010). Does IT outsourcing deliver economic value to firms? Journal of Strategic Information Systems, 19(2), 109-123. http:// dx.doi.org/10.1016/j.jsis.2010.05.003.

Instituto Brasileiro de Geografia e Estatística - IBGE. (2012). Dados sobre o município de São Borja. Recuperado em 8 de fevereiro de 2012, de http://www.ibge.gov.br/ cidadesat/topwindow.htm?1

Karassawa, N. (2001). Aspectos de qualidade da logística do turismo: estudo de caso (Dissertação de mestrado). Universidade Paulista, São Paulo.

Karvonen, V., Karvonen, M., \& Kraslawski, A. (2012). A tuned value Chain model for university based public research organisation. Case LUT CST. Journal of Technology Management and Innovation, 7(4), 164-175. http://dx.doi.org/10.4067/S0718-27242012000400013.

Kingman-Brundage, J. (1995). Service mapping: back to basics. In W. J. Glynn \& J. G. Barnes (Eds.), Understanding services management. Integrating marketing, organisational behaviour, operations and human resource management (pp. 223-234). New York: John Wiley \& Sons.

Kirchmer, M. (2004). E-business process networks: successful value chains through standards. Journal of Enterprise Information Management, 17(1), 20-30. http://dx.doi. org/10.1108/09576050410510926.

Koh, C. E., \& Nam, K. (2005). Business use of the internet: a longitudinal study from a value chain perspective. Industrial Management \& Data Systems. http://dx.doi. org/10.1108/02635570510575207.

Koh, S. C. L., Demirbag, M., Bayraktar, E., Tatoglu, E., \& Zaim, S. (2007). The impact of supply chain management practices on performance of SMEs. Industrial Management \& Data Systems, 107(1), 103 124. http://dx.doi.org/10.1108/02635570710719089.

Kung, F. H., Huang, C. L., \& Cheng, C. L. (2012). Assessing the green value chain to improve environmental performance; Evidence from Taiwan's manufacturing industry. International Journal of Development Issues, 11(2), 111-128. http://dx.doi.org/10.1108/14468951211241119.

Laffey, D. (2009). Click trading: A case study of Moneynet. The Journal of Strategic Information Systems, 18(1), 56-64. http://dx.doi.org/10.1016/j.jsis.2009.01.001.

Lee, H. L., \& Billington, C. (1993). Material Management in Decentralized Supply Chains. Operations Research, Catonsville, 41(5), 835-847. http://dx.doi.org/10.1287/ opre.41.5.835.

Lin, C., Tsai, H.-L., Wu, Y.-J. \& Kiang, M. (2012). A fuzzy quantitative VRIO-based framework for evaluating organizational activities. Management Decision, 50(8), 1396-1411. 
Lollar, J. G., Beheshti, H. M., \& Whitlow, B. J. (2010). The role of integrative technology in competitiveness. Competitiveness Review: An International Business Journal, 20(5), 423-433.

Luchi, R., \& Paladino, M. (2000). Improving competitiveness in a manufacturing value chain: issues dealing with the automobile sector in Argentina and Mercosul. Industrial Management \& Data Systems, 100(8), 349-358.

Mercado\&Eventos. (2012). MTur aguarda aprovação final para execução do PNT 2012-2015. Disponível em: Recuperado em 28 de fevereiro de 2013, de http:// www.mercadoeeventos.com.br/ site/noticias/view/84637

Novaes, A. G. (2004). Logística e gerenciamento da cadeia de distribuição: estratégia, operação e avaliação. Rio de Janeiro: Campus.

Oliveira, J. B., \& Leite, M. S. A. (2010). Modelo analítico de suporte à configuração e integração da cadeia de suprimentos. Gestão e Produção, 17(3), 447-463.

Pires, S. R. I. (2004). Gestão da cadeia de suprimentos. conceitos, estratégias, práticas e casos. São Paulo: Atlas.

Porter, M. E. (1985). Estratégia competitiva: instrumentos para análise da indústria e da concorrência. Rio de Janeiro: Campus.

Porter, M. E. (1999). Vantagem competitiva: criando e sustentando um desempenho superior (28 ed.). Rio de Janeiro: Campus.

Porter, M. E., \& Kramer, M. R. (2011). Creating shared value. Harvard Business Review, 89(1-2), 1-17.

Rainbird, M. (2004). A framework for operations management: the value chain. International Journal of Physical Distribution \& Logistics Management, 34(3), 337-345. http://dx.doi.org/10.1108/09600030410533628.

Rugman, A., Verbeke, A., \& Yuan, W. (2011). Reconceptualizing Bartlett and Ghoshal's Classification of National Subsidiary Roles in the Multinational Enterprise. Journal of Management Studies, 48(2), 253-277.

Rusko, R. T., Kyilänen, M., \& Saari, R. (2009). Supply chain in tourism destinations: the case of levi resort in finnish lapland. International Journal of Tourism Research, 11(1), 71-87. http://dx.doi.org/10.1002/jtr.677.

Santos, M. S., Leite, M. S. A., Lucena, A. D., \& Grilo, T. F., Jr. (2010). Evoluindo da cadeia de valor para cadeia de suprimentos. Revista Produção, 10(4), 753-778. http:// dx.doi.org/10.14488/1676-1901.v10i4.402.

Schneider, A. B., Carneiro, M. L., Serra, F. A. R., \& Ferreira, M. P. (2009). Estratégia competitiva: Michael Porter 30 anos depois. Revista de Administração da UFSM, 2(2), 298-326.

Shostack, G. L. (1984). Designing services that deliver. Harvard Business Review, 84115, 133-139.

Sigala, M. (2008). A supply chain management approach for investigating the role of tour operators on sustainable tourism: the case of TUI. Journal of Cleaner Production, 16(15), 1589-1599. http://dx.doi.org/10.1016/j. jclepro.2008.04.021.

Silva, C. A. V., \& Musetti, M. A. (2003). Logística militar e empresarial: uma abordagem reflexiva. Revista de Administração, 38(4), 343-354.

Silva, M. B. R. O. (2008). Evento como estratégia na comunicação das organizações: modelo de planejamento e organização. Recuperado em 1 de fevereiro de 2012, de http://www.portal-rp.com.br/bibliotecavirtual/ eventosecerimonias/0321.htm

Simchi-Levi, D., Kaminsky, P., \& Simchi-Levi, E. (2006). Cadeia de suprimentos: projetos e gestão. Porto Alegre: Bookman.

Song, H., Liu, J., \& Chen, G. (2013). Tourism value chain governance: review and prospects. Journal of Travel Research, 52(1), 15-28. http://dx.doi. org/10.1177/0047287512457264.

Souza, L. L. C., \& Rados, G. J. V. (2011). Mecanismos que sustentam a competitividade de uma cadeia de valor terceirizada: o caso da maior distribuidora de energia elétrica do Brasil. GESTÃO.Org: Revista Eletrônica de Gestão Organizacional, 9(3), 505-533.

Souza, M. A., \& Mello, E. (2011). Análise da cadeia de valor: um estudo no âmbito da gestão estratégica de custos de empresas da construção civil da grande Porto Alegre. Revista Contemporânea em Contabilidade, 8(15), 11-39.

Stock, L. T. (2009). Logística integrada em eventos: um estudo de caso do Festival de Dança de Joinville - SC. (Dissertação de mestrado). Universidade do Vale do Itajaí, Balneário Camboriú.

Taylor, D. H. (2005). Value chain analysis: an approach to supply chain improvement in agri-food chains. International Journal of Physical Distribution \& Logistics Management, 35(10), 744-761. http://dx.doi. org/10.1108/09600030510634599.

Telles, R. M. S., \& Previatti, C. B. (2012). Organização de eventos: uma atividade em expansão na cidade terciária - Caso São Paulo (SP). In Anais do IX Seminário da Associação Nacional de Pesquisa e Pós-graduação em Turismo (pp. 1-17). São Paulo: ANPTUR.

Triviños, A. N. S. (2009). Introdução à pesquisa em ciências sociais: a pesquisa qualitativa em educação. São Paulo: Atlas.

Vadi, M., \& Turk, K. (2009). Behaviour patterns in Estonian enterprises from the perspective of the value chain. Baltic Journal of Management, 4(1), 34-50. http:// dx.doi.org/10.1108/17465260910930430.

Varandas, A. Jr., Salermo, M. S., \& Cauchick Miguel, P. A. (2014). Análise da gestão da cadeia de valor da inovação em uma empresa do setor siderúrgico. Gestão e Produção, 21(1), 1-18. 
Viana, J. G. A., Revillion, J. P. P., \& Silveira, V. C. P. (2013). Alternativa de estruturação da cadeia de valor da ovinocultura no Rio Grande do sul. Revista Brasileira de Gestão e Desenvolvimento Regional, 9(1), 187-210.

Voss, C., Tsikriktsis, N., \& Frohlich, M. (2002). Case Research in Operations Management. International Journal of Operations \& Production Management, 22(2), 195-219. http://dx.doi.org/10.1108/01443570210414329.

Waheed, Z., \& Fernie, S. (2009). Knowledge based facilities management. Facilities, 27(7), 258-266.

Walsh, P. R. (2011). Creating a "values" chain for sustainable development in developing nations: where Maslow meets Porter. Environment, Development and Sustainability, 13(4), 789-805.

Watt, D. C. (2004). Gestão de eventos em lazer e turismo. Porto Alegre: Bookman.
Wood, T., Jr. (2004). Mudança organizacional (4 ed.). São Paulo: Atlas.

World Travel \& Tourism Council. (2013). Economic impact analysis. Recuperado em 16 de fevereiro de 2013, de http://www.wttc.org/research/economic-research/ economic-impact-analysis/

Yin, R. K. (2008). Case study research: designs and methods ( 3 ed.). Londres: Sage Publications.

Yin, R. K. (2010). Estudo de caso: planejamento e métodos (4 ed.). Porto Alegre: Bookman.

Zokaei, A. K., \& Simons, D. W. (2006). Value chain analysis in consumer focus improvement: a case study of the UK red meat industry. The International Journal of Logistics Management, 17(2), 141-162. http://dx.doi. org/10.1108/09574090610689934. 